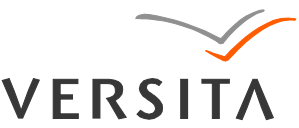

\title{
THERMALLY ASSISTED OSL: A POTENT TOOL FOR IMPROVEMENT IN MINIMUM DETECTABLE DOSE AND EXTENSION OF DOSE RANGE OF $\mathrm{Al}_{2} \mathrm{O}_{3}: \mathrm{C}$
}

\author{
ANUJ SONI ${ }^{1}$, DEVESH R. MISHRA ${ }^{1}$, BHUWAN C. BHATT ${ }^{2}$, SHIV K. GUPTA ${ }^{3}$, \\ NARENDRA S. RAWAT ${ }^{\mathbf{1}}$, MUKUND S. KULKARNI ${ }^{\mathbf{1}}$ and DEVANAND N. SHARMA ${ }^{\mathbf{1}}$ \\ ${ }^{1}$ Radiological Physics and Advisory Division, Bhabha Atomic Research Centre, Trombay, Mumbai, India-400085 \\ ${ }^{2} 2$ DST Fellow, Clo Radiological Physics and Advisory Division, Bhabha Atomic Research Centre, Trombay, Mumbai, India-400085 \\ ${ }^{3}$ Technical Physics Division, Bhabha Atomic Research Centre, Trombay, Mumbai, India-400085
}

Received 31 January 2013

Accepted 2 September 2013

\begin{abstract}
The influence of electron-phonon interaction on the shape of the optically stimulated luminescence decay curve of $\mathrm{Al}_{2} \mathrm{O}_{3}: \mathrm{C}$ has been studied using thermally assisted optically stimulated luminescence (TA-OSL). The minimum detectable dose (MDD) of a phosphor depends on the standard deviation of the background signal which affects the signal-to-noise ratio. The standard deviation of the background signal reduces at lower stimulation light intensity while the readout time increases. Further, measurement at higher temperature enhances the OSL signal with faster decay due to the temperature dependence of photo-ionization cross-section. To achieve the same decay constant and more signal, the temperature of measurement was raised. As a result of lowering the stimulation intensity at higher temperature $\left(85^{\circ} \mathrm{C}\right)$ the overall $\mathrm{MDD}$ of $\alpha-\mathrm{Al}_{2} \mathrm{O}_{3}: \mathrm{C}$ was found to improve by 1.8 times. For extension of dose linearity in higher range, deeper traps were studied by simultaneous application of CW-OSL and thermal stimulation up to $400^{\circ} \mathrm{C}$, using a linear heating rate of $4 \mathrm{~K} / \mathrm{s}$. By using this method, two well defined peaks at $121^{\circ} \mathrm{C}$ and $232^{\circ} \mathrm{C}$ were observed. These TA-OSL peaks have been correlated with two deeper defects which can be thermally bleached at $650^{\circ} \mathrm{C}$ and $900^{\circ} \mathrm{C}$ respectively. These deeper defects are stable up to $500^{\circ} \mathrm{C}$, so they can store absorbed dose information even if the sample is inadvertently exposed to light or heat. The dose vs. TA-OSL response from deep traps of $\alpha-\mathrm{Al}_{2} \mathrm{O}_{3}: \mathrm{C}$ was found to be linear up to $10 \mathrm{kGy}$, thus extending its application for high dose dosimetry.
\end{abstract}

Keywords: decay constant, photo-ionization cross-section, thermally assisted OSL (TA-OSL).

\section{INTRODUCTION}

Optically stimulated luminescence (OSL) is a phenomenon directly associated with the presence of metastable trapped charges in wide band gap insulators/semiconductors. The conventional way of stimulat-

Corresponding author: A. Soni

e-mail: anujsoni.phy@gmail.com ing a phosphor is continuous wave (CW)-OSL mode, where the stimulation light intensity is held constant with respect to time and decay of OSL signal thus recorded. The decay constant of such a CW-OSL curve under first order kinetics contains information about photoionization cross-section (probability of interaction of incident photon with the trapped electron in the trap) of traps participating in OSL phenomenon. The relatively 
long time of CW-OSL recording generates considerable amount of background counts due to scattering of stimulating light from the sample holder, LED light leakage due to inadequate optical filtering of the stimulated light by optical filter combination. This results in a degradation of the overall signal to noise ratio of the instrument. The minimum detectable dose (MDD) of a phosphor depends on the total signal and the standard deviation of the background signal of the readout instrument. The standard deviation in the background signal and thus the signal-tonoise ratio can be improved considerably by taking CWOSL readout at lower stimulation intensities. However, this reduction in stimulation intensity affects the decay constant and increases the readout time and total signal also gets affected. The decay shape is dependent upon the sample, the absorbed dose, the illumination intensity and the temperature of readout McKeever et al., (1997). The dependence of the optical excitation probability on temperature is reported in the literature and mostly assigned to the so-called thermal assistance or to the presence of the shallow trap that is thermally depopulated at the temperatures of OSL measurement which leads to give more signal as compared to that at room temperature (RT). Bailey (2001) and McKeever et al. (1997) give brief reviews of some attempts that were undertaken in order to explain the experimentally observed changes of the OSL decay rate with measurement temperature. The paper of McKeever et al. (1997) also shows that shallow traps can strongly affect the shape of OSL curves in the case of complex systems. The related effects depend not only on the temperature but also on the intensity of stimulation light and on the radiation dose applied for the excitation of OSL. In general, there are two ideas in this approach, one postulating the existence of an intermediate shallow level (Hütt et al., 1988; Poolton et al., 1995) and another one referring to the assistance of lattice vibrations but eventually, in the experiment interpretation, introducing an excited state of trap with a definite energy (Spooner, 1994). Although the first proposed mechanism is possible in some particular cases, the second one seems to be more fundamental, at least in the idea that the temperature dependence observed in the production of OSL is inherent to the photo-ionization mechanism. Spooner (1994) studied the temperature dependent nature of photoionization cross-section in quartz by taking elevated temperature isothermal CW-OSL measurements and suggested that the temperature dependence of photo-ionization cross-section follows the Arrhenius law. It is suggested that the photo-ionization cross-section consists basically of two parts - one is temperature independent and the other depends on temperature exponentially. This dependence of photo-ionization cross-section of intermediate traps on the decay constant can be utilized for the improvement in the MDD of various OSL phosphors.

$\alpha-\mathrm{Al}_{2} \mathrm{O}_{3}: \mathrm{C}$ is a well-established passive TL and OSL detector widely used for various applications in radiation dosimetry. The intermediate traps in $\alpha-\mathrm{Al}_{2} \mathrm{O}_{3}: \mathrm{C}$, called dosimetric traps, are reported to have the MDD of $\sim 20 \mu \mathrm{Gy}$ and show sub-linear dose response for doses $>1$ Gy (Akselrod et al., 1990) using the CW-OSL technique, hence putting limitations in the high dose range. In $\alpha-\mathrm{Al}_{2} \mathrm{O}_{3}: \mathrm{C}$, the deeper traps were found to give their presence at $873 \mathrm{~K}$ and $1173 \mathrm{~K}$ respectively (Akselrod et al., 1993). Such deep traps have a large thermal trap depth and are difficult to access by TL. Secondly, at such high temperatures the loss of signal due to very high thermal quenching (Akselrod et al., 1998) and interference of high infrared background makes TL measurements difficult beyond $750^{\circ} \mathrm{C}$. Apart from this, the conventional OSL technique at RT is also incapable of accessing such deep traps, as the photo-ionization cross-section of these traps is expected to be very low at RT. The present work describes a new experimental method using temperature dependence of photo-ionization cross-section to access the signal from deep traps without heating the sample to temperatures higher than $400^{\circ} \mathrm{C}$ and limiting the readout time up to $120 \mathrm{~s}$. The measured signal can be used to extend the applicability of $\alpha-\mathrm{Al}_{2} \mathrm{O}_{3}: \mathrm{C}$ powdered OSL phosphor for accident dosimetry in harsh conditions of light exposure and temperatures.

\section{TEMPERATURE DEPENDENCE MODEL FOR $\mathrm{Al}_{2} \mathrm{O}_{3}: \mathrm{C}$}

In general, the temperature dependence of OSL is complicated if a sample contains a significant number of shallow traps which become inactive as the temperature increases. When OSL measurements are carried out at RT, a long tail in the OSL curve is often observed. This can be attributed to the influence of shallow traps which localize charges released during illumination and slowly release them again at a rate determined by the trap depth and the sample temperature. Since at low temperatures, where the half-life of the charge in the shallow traps is much longer than the decay time, a small OSL signal is obtained due to trapping in the low temperature traps. At high temperatures, where the trap lifetime is very small, a much increased OSL is obtained. The signal increases initially then decays non-exponentially. In this way shallow traps may slow down the OSL decay processes. Furthermore, shallow traps give rise to a temperature dependent OSL component since at higher temperatures they become less effective at trapping charge. Measurement at elevated temperature reduces the effect of the shallow traps considerably since these states cannot store any charge which is optically transferred to them from deeper traps. These effects were shown in computer simulations by McKeever and Morris (1994) and were demonstrated experimentally for $\mathrm{A}_{2} \mathrm{O}_{3}$ by Markey et al. (1996).

Another way, in which a thermally activated process may occur, is via a thermally assisted transition into the delocalized band. For example, OSL is observed from feldspars following illumination with infra-red light. At 
these wavelengths direct optical excitation from the deep trap into the conduction band is unlikely and thus a thermally assisted transition was postulated by Hütt et al. (1988) in which the IR excites the electron into an excited state, from where it may be thermally excited into the delocalized band with a thermally activated probability which follows an $\exp \left\{-E_{A} / k T\right\}$ law. In either of the above cases, the OSL is seen to be thermally activated, but the interpretation of the activation energy is quite different. Spooner (1994) postulated the existence of an array of available states in the ground state of the trap. The upper levels of this array are accessed at higher temperatures, with activation energy, requiring a smaller optical energy to excite the charges into the delocalized bands. In case of $\mathrm{Al}_{2} \mathrm{O}_{3}: \mathrm{C}$, the stimulation is not restricted to one particular wavelength, transition of charges from the deeper traps to the higher electronic states is unlikely, instead it moves to a higher vibrational state of the same electronic state as an effect of temperature. Mishra et al. (2011a) formulated the theory of TA-OSL for $\mathrm{Al}_{2} \mathrm{O}_{3}: \mathrm{C}$. Fig. 1 shows the energy level diagram representing the electronic transition involved in the photo-transfer process from various traps in $\alpha-\mathrm{Al}_{2} \mathrm{O}_{3}$ : C. The various energy levels have been reported by earlier investigators (Yukihara et al., 2003) which have been used to plot Fig. 1. The TA-OSL model for $\alpha-\mathrm{Al}_{2} \mathrm{O}_{3}$ : C showing the vibrational level of deep energy level $\mathrm{DT}_{1}$ and $\mathrm{DT}_{2}$ defects participating in thermally assisted OSL.

\section{EXPERIMENTAL DETAILS}

The dosimetry grade single crystal of $\alpha-\mathrm{Al}_{2} \mathrm{O}_{3}: \mathrm{C}$ (TLD 500, Landauer Inc.; $5 \mathrm{~mm}$ in diameter, $0.8 \mathrm{~mm}$ thick) was irradiated using a calibrated ${ }^{90} \mathrm{Sr} /{ }^{90} \mathrm{Y}$ beta source. The TA-OSL and CW-OSL was recorded at various temperatures and various stimulation intensities for the irradiated samples in integrated TL/OSL measurement set-up (Kulkarni et al., 2007) consisting of a high intensity $\left(50 \mathrm{~mW} / \mathrm{cm}^{2}\right)$ blue light emitting diode $\left(\lambda_{\mathrm{p}}=470 \mathrm{~nm}, \Delta \lambda=20 \mathrm{~nm}\right)$ cluster as a stimulating light source. The samples were optically bleached with $\sim 100 \mathrm{~mW} / \mathrm{cm}^{2}$ blue LED $(470 \mathrm{~nm})$ light for $10 \mathrm{~min}$., before the irradiation. The TL and TA-OSL curves were recorded at a constant heating rate of $4 \mathrm{~K} / \mathrm{s}$ and all OSL measurements were performed in the $\mathrm{CW}$ - OSL mode. The light intensity at the sample position was measured using an $\mathrm{Si}$ photodiode (OSD-5) giving approximately $48.8 \mathrm{~mW} / \mathrm{cm}^{2}$. The GG-435 and UG-1 optical filters were used across the LED cluster and PMT to prevent the stimulating light from reaching the PMT.

\section{RESULTS AND DISCUSSIONS}

\section{Signal to Noise Ratio (S/N) Analysis for CW-OSL}

The overall background in the recorded OSL signal can be expressed as (Mishra et al., 2011b)

OSL counts $\left(\mathrm{N}_{\mathrm{OSL}}\right)=\mathrm{N}_{\mathrm{PMT}}+\mathrm{N}_{\mathrm{sc}}+\mathrm{N}_{\mathrm{e}}$,

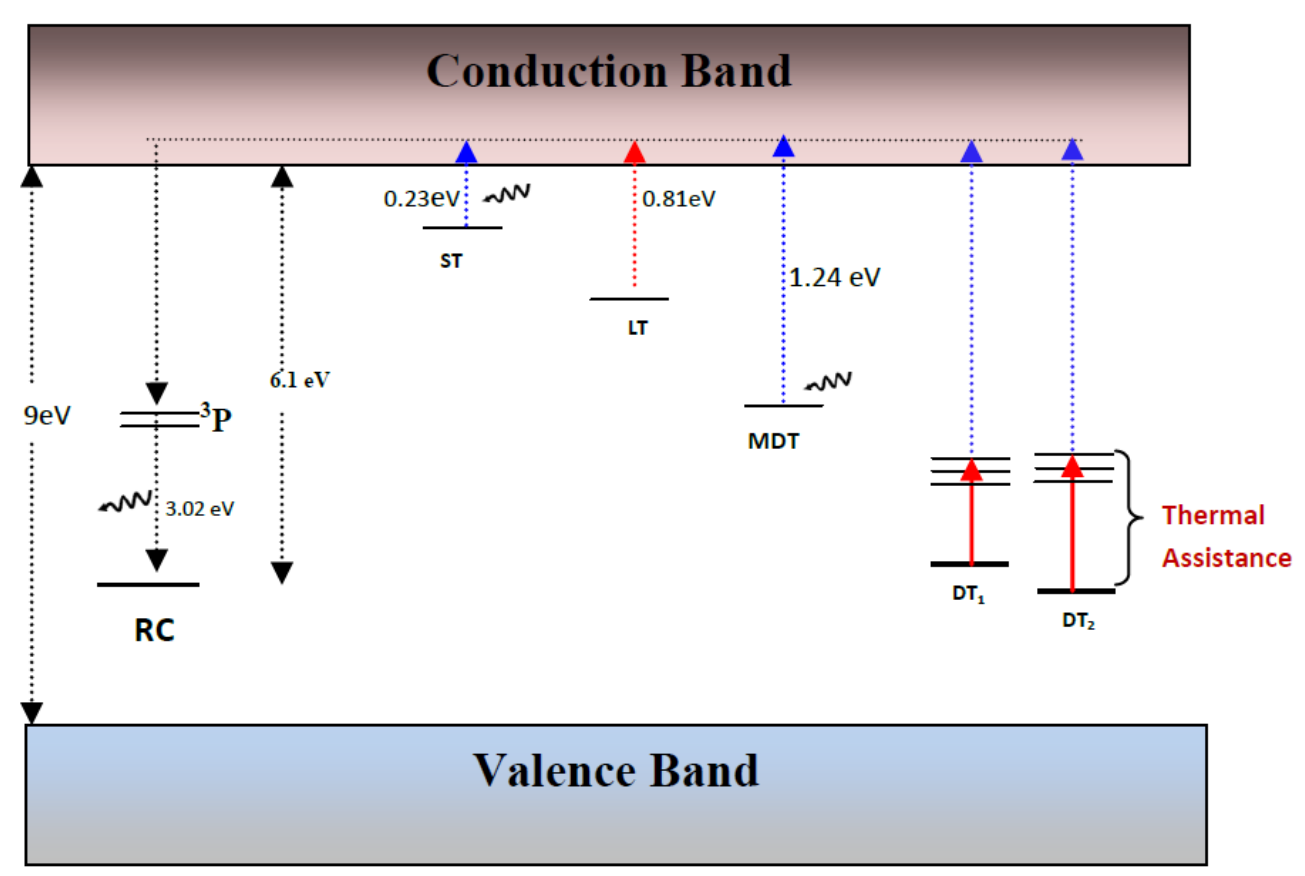

Fig.1. Energy level diagram showing various electronic transition involved in the phototransfer process including thermal assistance from deep traps in $\alpha-\mathrm{Al}_{2} \mathrm{O}_{3}: \mathrm{C}$ powder. 
where $\mathrm{N}_{\mathrm{PMT}}$ - dark counts of the photomultiplier tube (PMT), $\mathrm{N}_{\mathrm{sc}}$ - background signal generated due to scattering of stimulation light from sample / sample holder and inadequate optical filter action which does not fully cut off stimulation wavelength, $\mathrm{N}_{\mathrm{e}}$ - background counts contributed due to electronics hardware / circuit used for stimulation as well as detection of PMT output signals at the amplifier and pre-amplifier.

The dark counts of the PMT $\left(N_{P M T}\right)$ can be reduced by properly controlling the bias voltage, providing adequate cooling of the PMT, shielding it against external magnetic field by $\mu$-shielding material. The major background component in OSL reader systems is the counts originated due to leakage of stimulation light $\left(\mathrm{N}_{\mathrm{sc}}\right)$. It depends on many factors; most important among them is the selection of the cut-off optical filters. The contribution of these background signals increases with an increase in the value of stimulation intensity and reflectivity of the sample/sample holder. The contribution of this signal can be reduced substantially by reducing the reflectivity of the sample holder and stabilizing the stimulation intensity, so that the large part of this background signal can be subtracted as a constant background. Therefore, in brief, the background counts generated due to scattering of stimulation light $\mathrm{N}_{\mathrm{sc}}$ can be reduced if the total integrated stimulation flux incident on sample during readout is reduced without compromising the total OSL signal. For the S/N consideration, we have to compare the $\mathrm{S} / \mathrm{N}$ for higher stimulation intensity to that at lower stimulation intensity at room temperature (RT) as follows

$$
\frac{{ }^{R T}\left(S_{H} / N_{H}\right)}{{ }^{R T}\left(S_{L} / N_{L}\right)}=k
$$

where $S_{H} / \mathrm{N}_{H}$ and $S_{L} / N_{L}$ are the signal to noise ratios for higher and lower stimulation intensity, respectively. However assuming the first order decay and acquisition of complete area lead to same amount of signal $\left(\mathrm{S}_{\mathrm{H}}=\mathrm{S}_{\mathrm{L}}\right)$, i.e., the dose is the same for both cases, the values of $k$ which is the measure of the figure of merit is given by

$$
\frac{{ }^{R T}\left(S_{H} / N_{H}\right)}{{ }^{R T}\left(S_{L} / N_{L}\right)}=k=\frac{{ }^{R T} N_{L}}{{ }^{R T} N_{H}}
$$

So the value of $\mathrm{k}$ is nothing but the ratio of noise at lower stimulation intensity to that at higher stimulation intensity. Now the differential noise for any stimulation intensity at RT is given by

$$
\begin{aligned}
& \frac{{ }^{R T} d N}{d t_{R}}=N_{s c}+N_{P M T}+N_{e} \\
& { }^{R T} N=\int_{0}^{t R}\left(N_{s c}+N_{P M T}+N_{e}\right) d t_{R} \\
& { }^{R T} N=t_{R}\left(N_{s c}+A\right)
\end{aligned}
$$

where $\mathrm{A}=\mathrm{N}_{\mathrm{PMT}}+\mathrm{N}_{\mathrm{e}}$, which is independent of stimulation intensity whereas $\mathrm{N}_{\mathrm{sc}}$ is a function of stimulation intensity and $t_{R}$ is total time of readout. Therefore the value of $k$ is give by

$$
\frac{{ }^{R T} N_{L}}{{ }^{R T} N_{H}}=\frac{t_{R L}\left(N^{L}{ }_{s c}+A\right)}{t_{R H}\left(N^{H}{ }_{s c}+A\right)}
$$

where, $\mathrm{N}^{\mathrm{L}}{ }_{\text {sc }}$ and $\mathrm{N}^{\mathrm{H}}{ }_{\text {sc }}$ are the scattering noise for lower and higher stimulation intensity respectively and $t_{R L}$ and $t_{R H}$ are the time of readout for lower and higher stimulation intensity respectively. As $\mathrm{N}_{\mathrm{sc}} \gg \mathrm{A}$, the value of $\mathrm{k}$ can be written as

$$
\begin{gathered}
\frac{{ }^{R T} N_{L}}{{ }^{R T} N_{H}}=\left(\frac{t_{R L}}{t_{R H}}\right)\left(\frac{N^{L}{ }_{s c}}{N^{H}{ }_{s c}}\right) \\
k=\eta^{*} \xi
\end{gathered}
$$

where,

$$
\eta=\left(\frac{t_{R L}}{t_{R H}}\right) \text { and } \xi=\left(\frac{\mathrm{N}_{\mathrm{sc}}^{\mathrm{L}}}{\mathrm{N}_{\mathrm{sc}}^{\mathrm{H}}}\right)
$$

where $\xi$ is independent of temperature, while $\eta$ is a function of temperature. At RT $\eta>1\left(t_{R L}>t_{R H}\right)$ for taking complete signal and $\xi<1$ as per Fig. 3 of Mishra et al. (2011b).

Evaluating $\mathrm{k}$ for $48 \mathrm{~mW} / \mathrm{cm}^{2}$ and $30 \mathrm{~mW} / \mathrm{cm}^{2}$ at RT from Eq. 9 by putting $\mathrm{t}_{30}=90 \mathrm{~s}, \mathrm{t}_{48}=70 \mathrm{~s}, \mathrm{~N}_{\mathrm{sc}}\left(\mathrm{P}_{30}\right)=220$ and $\mathrm{N}_{\mathrm{sc}}\left(\mathrm{P}_{48}\right)=380$ from Fig. 3 of Mishra et al. (2011b), we obtain $\mathrm{k}=0.74$. Therefore the signal to noise ratio (at RT) at higher stimulation intensity is slightly better than that at lower stimulation intensity. This value of $\mathrm{k}$ is for commercial reader (having highest detection threshold) where one will get almost the same signal $\left(\mathrm{S}_{\mathrm{H}}=\mathrm{S}_{\mathrm{L}}\right)$ for two values of stimulation intensities so we canceled the $\mathrm{S}$ term in Eq. 2. However for moderate sensitivity reader system (laboratory reader system) signal (S) is never the same $\left(S_{H} \neq S_{L}\right)$ for two different values of stimulation intensities due to the problem of detection threshold of the PMT. In such cases one cannot cancel S in Eq. 2 for two different intensities. S will be higher for higher stimulation intensity as compared to that at lower stimulation intensity. Thus, for practical reader system $\mathrm{k}$ is slightly greater than 1 due to $S_{H}>S_{L}$. For such reader system we get higher signal to noise ratio at higher stimulation intensities.

Now considering the effect of temperature in Eq. 9, the value of $\eta \sim 1$ at elevated temperature, i.e., $\left({ }^{\mathrm{TH}} \mathrm{t}_{\mathrm{RL}}=\mathrm{t}_{\mathrm{RH}}\right)$ due to temperature dependence of photoionization cross-section (where ${ }^{\mathrm{TH}} \mathrm{t}_{\mathrm{RL}}$ is the time taken to record the complete signal at lower stimulation intensity with higher temperature). As the signal increases at high temperature due to thermally assisted OSL we have $\left({ }^{\mathrm{TH}} \mathrm{S}_{\mathrm{L}}\right.$ $\sim \mathrm{S}_{\mathrm{H}}$ ). Therefore the value of $\mathrm{k}$ at a higher temperature will only depend on $\xi$ which is smaller than 1 . Thus, the 
signal to noise ratio with lower stimulation intensities at elevated temperature is better than the one with higher stimulation intensities at lower (or room) temperature.

\section{TA-OSL: Improvement in MDD}

The MDD of any phosphor not only depends on the defects, quality of the material but also on the readout technique and the instrument used. The relatively long time of CW-OSL recording generates considerable amount of background counts due to scattering of stimulating light from sample holder. This results in degradation of the overall signal to noise ratio. The contribution of background signals increases with increase in the value of stimulation intensity and reflectivity of sample/sample holder. The contribution of this signal can be reduced substantially by reducing the reflectivity of sample holder and statistically stabilizing the stimulation intensity, so that the large part of this background signal can be subtracted as a constant background. The reduction in stimulation light intensity and hence the scattering component reduces the standard deviation in the total background signal. Fig. 2 shows the reduction in standard deviation in background count as a function of $\mathrm{CW}$-stimulation light intensity with sample stimulated for fixed time at $25^{\circ} \mathrm{C}$. However, the reduction in stimulation light intensity increases the readout time due to the dependence of decay constant of OSL signal on the former. The decay constant depends on the photo-ionization cross-section of the OSL active traps in the phosphor participating in OSL phenomenon and thus on the readout temperature due to the temperature dependence of photo-ionization crosssection. Fig. 3 shows the CW-OSL at various temperatures for a given set of experimentally evaluated (Mishra et al., 2011a) values, with fixed CW stimulation intensity $\phi_{\mathrm{o}}=48 \mathrm{~mW} / \mathrm{cm}^{2}$ of $470 \mathrm{~nm}$ light. Inset of Fig. 3 shows $\mathrm{CW}-\mathrm{OSL}$ at various stimulation intensities at $25^{\circ} \mathrm{C}$. In order to achieve the same decay constant for two sets of measurements for $\alpha-\mathrm{Al}_{2} \mathrm{O}_{3}: \mathrm{C}$ i.e. to take the OSL measurement in the same time at lower stimulation light intensity as that taken for higher light intensity, the temperature of measurement for $\alpha-\mathrm{Al}_{2} \mathrm{O}_{3}$ :C for the former was raised. Besides, the increase of readout temperature does not affect the standard deviation in the background signal of OSL readout. The optimized elevated temperature for $\alpha-\mathrm{Al}_{2} \mathrm{O}_{3}: \mathrm{C}$ was found to be $85^{\circ} \mathrm{C}$ as the main dosimetric peak starts giving signal $90^{\circ} \mathrm{C}$ onwards due to depletion of its filled traps. Therefore the decay constant of the $\mathrm{CW}-\mathrm{OSL}$ was increased without compromising on the total OSL signal. Fig. 4 shows the CW-OSL readout of $\alpha$ $\mathrm{Al}_{2} \mathrm{O}_{3}: \mathrm{C}$ at two different stimulation intensities 30 and 48 $\mathrm{mW} / \mathrm{cm}^{2}$ at $25^{\circ} \mathrm{C}$, showing the change in the CW-OSL decay constant as a function of stimulation intensity. The $\mathrm{CW}-\mathrm{OSL}$ signal taken at $30 \mathrm{~mW} / \mathrm{cm}^{2}$ (lower stimulation intensity) takes more time to decay to the same level as compared to that at higher intensity $\left(48 \mathrm{~mW} / \mathrm{cm}^{2}\right)$. In order to achieve the same decay constant, i.e. to take the OSL measurement in the same time at $30 \mathrm{~mW} / \mathrm{cm}^{2}$ stimu- lation light intensity as that at $48 \mathrm{~mW} / \mathrm{cm}^{2}$ light intensity, the temperature of measurement for $\alpha-\mathrm{Al}_{2} \mathrm{O}_{3}: \mathrm{C}$ was raised (inset of Fig. 4). At even lower stimulation power $\left(<30 \mathrm{~mW} / \mathrm{cm}^{2}\right)$, the standard deviation in the background further decreases which can further improve the MDD. However, at even lower intensities, the decay time increases accordingly, i.e. it will take more time to take the complete signal, which will demand temperature more than $85^{\circ} \mathrm{C}$ to reduce the decay constant. In case of $\alpha-\mathrm{Al}_{2} \mathrm{O}_{3}: \mathrm{C}$, we restricted readout temperature at $85^{\circ} \mathrm{C}$ only as the main dosimetric peak starts giving the signal from $90^{\circ} \mathrm{C}$ onwards. On taking the OSL signal at temperature more than $85^{\circ} \mathrm{C}$, the signal will be lost in TL mode,

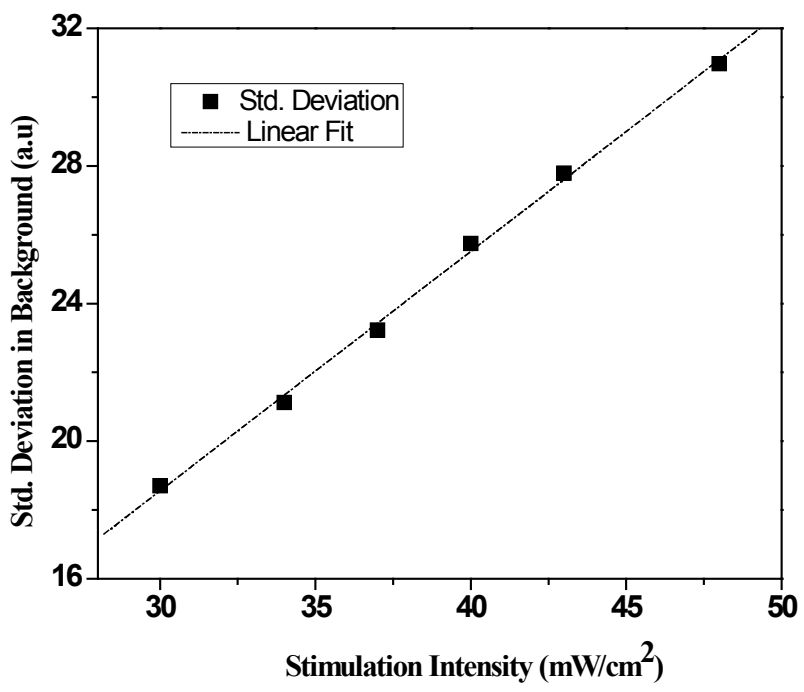

Fig. 2. Standard deviation in background count vs. CW-stimulation light intensity with sample stimulated for fixed time at $25^{\circ} \mathrm{C}$.

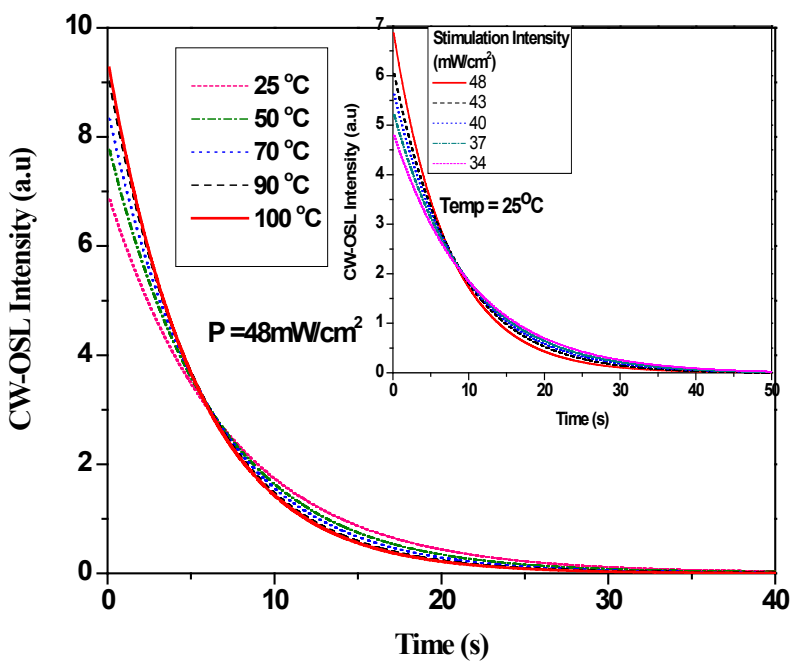

Fig. 3. Numerically simulated CW-OSL at various temperatures for a given set of experimentally evaluated (Mishra et al., 2011a) values, with fixed CW stimulation intensity $\phi_{0}=48 \mathrm{~mW} / \mathrm{cm}^{2}$ of $470 \mathrm{~nm}$ light. Inset figure shows CW-OSL at various stimulation intensities at $25^{\circ} \mathrm{C}$. 
so $85^{\circ} \mathrm{C}$ is the optimized temperature for $\alpha-\mathrm{Al}_{2} \mathrm{O}_{3}: \mathrm{C}$. However, for those phosphors in which the dosimetric peaks starts at even higher temperatures such as $150^{\circ} \mathrm{C}$ onwards, one could go to even lower stimulation intensities $\left(<30 \mathrm{~mW} / \mathrm{cm}^{2}\right)$ to further improve the MDD.

Table 1 gives the variation of decay constant at various temperatures and optical power. Henceforth this technique will be referred to as thermally assisted CWOSL (TA-CWOSL). As a result of lowering the stimulation intensity $\left(30 \mathrm{~mW} / \mathrm{cm}^{2}\right)$, the standard deviation in the background signal was found to be improved 1.8 times and taking $\mathrm{CW}-\mathrm{OSL}$ at higher temperature $\left(85^{\circ} \mathrm{C}\right)$ increases the decay constant (i.e. the readout is faster). Thus the overall MDD of $\alpha-\mathrm{Al}_{2} \mathrm{O}_{3}: \mathrm{C}$ by TA-CWOSL was found as $11.4 \mu \mathrm{Gy}$ as compared to $20 \mu \mathrm{Gy}$ by CW-OSL method i.e., improved 1.8 times. Fig. 5 shows the improvement in MDD as a function of stimulation intensity and experimentally evaluated values of decay constant at various combination of readout temperature and stimula-

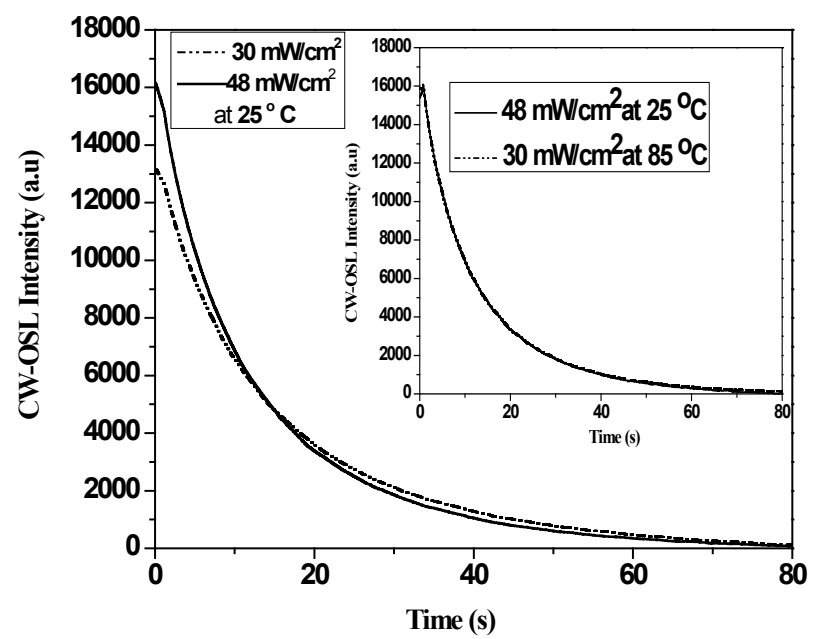

Fig. 4. Experimentally evaluated $\mathrm{CW}-\mathrm{OSL}$ of $\alpha-\mathrm{Al}_{2} \mathrm{O}_{3}: \mathrm{C}$ at two different stimulation intensities at $25^{\circ} \mathrm{C}$, showing the change in the $\mathrm{CW}$-OSL decay constant as a function of stimulation intensity. Inset figure shows the effect of temperature to achieve the same CW-OSL decay constant at different stimulation intensities. tion intensity. The MDD was measured in the following way:

1) Measurements of background on five freshly annealed, unirridiated $\mathrm{Al}_{2} \mathrm{O}_{3}: \mathrm{C}$ detectors to determine 3 standard deviations of the background signal (X).

2) Expose six annealed crystals to a dose of $\mathrm{D}=500 \mu \mathrm{Gy}$ and determine mean output of these detectors $\mathrm{Y} / \mathrm{D}\left(\mu \mathrm{Gy}^{-1}\right)$.

3) Calculate MDD as : $\operatorname{MDD}(\mu G y)=X^{*} D / Y$

Table 2 shows the comparison of MDD and the respective OSL readout time for various stimulation techniques. It is clear that POSL gives the best signal to noise ratio and thus the MDD and is reported as $5 \mu \mathrm{Gy}$ (McKeever et al., 1996). The MDD for LM-OSL was compared with that of CW-OSL by recording them for same final stimulation intensity and integration time and it was found that LM-OSL gives lower MDD as compared to CW-OSL a factor of 1.3 and comes out as $15.38 \mu \mathrm{Gy}$. Further, NL-OSL has been reported to give 1.2 times better MDD as compared to LM-OSL (Mishra et al., 2011b) and thus comes out as $12.80 \mu \mathrm{Gy}$.

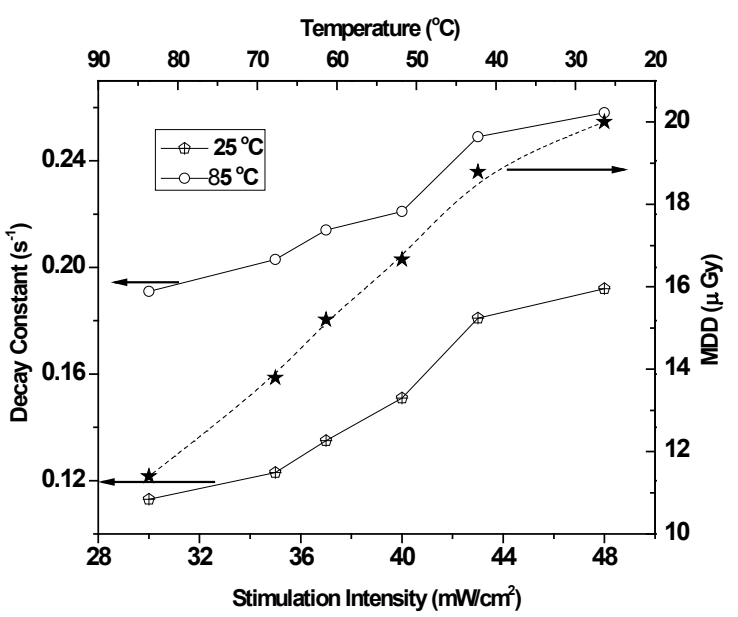

Fig. 5. Experimentally evaluated $\mathrm{CW}-\mathrm{OSL}$ decay constant of $\alpha-\mathrm{Al}_{2} \mathrm{O}_{3}: \mathrm{C}$ at various stimulation intensities and two different temperatures $\left(25^{\circ} \mathrm{C}\right.$, $85^{\circ} \mathrm{C}$ ) showing the change in the CW-OSL decay constant as a function of stimulation intensity. The other graph shows the improvement in $M D D$ as a function of stimulation intensity.

Table 1. Variation of Decay constant at various temperatures and optical power (CW-OSL and TA-CWOSL method).

\begin{tabular}{|c|c|c|c|c|c|c|c|c|}
\hline \multirow{2}{*}{$\begin{array}{c}\text { Power } \\
\left(\mathrm{mW} / \mathrm{cm}^{2}\right)\end{array}$} & \multicolumn{4}{|c|}{ Decay Constant $(\mathrm{f}=\sigma \varphi)\left(\mathbf{s}^{-1}\right)$} & \multirow[b]{2}{*}{ Std Dev. in Bkg } & \multirow{2}{*}{$\begin{array}{l}\text { Improvement } \\
\text { factor in MDD }\end{array}$} & \multirow{2}{*}{$\begin{array}{l}\text { MDD of } \mathrm{Al}_{2} \mathrm{O}_{3}: \mathrm{C} \\
\quad(\mu \mathrm{Gy})\end{array}$} & \multirow{2}{*}{$\begin{array}{l}\text { Respective temperatures } \\
\left({ }^{\circ} \mathrm{C}\right) \text { for same decay } \\
\text { constant }(0.192)\end{array}$} \\
\hline & $25^{\circ} \mathrm{C}$ & $45^{\circ} \mathrm{C}$ & $60^{\circ} \mathrm{C}$ & $85^{\circ} \mathrm{C}$ & & & & \\
\hline 48 & 0.192 & 0.221 & 0.245 & 0.258 & 30.96 & 1 & 20.00 & 25 \\
\hline 43 & 0.181 & 0.210 & 0.232 & 0.249 & 28.79 & 1.07 & 18.79 & 35 \\
\hline 40 & 0.151 & 0.183 & 0.208 & 0.221 & 25.65 & 1.20 & 16.66 & 50 \\
\hline 35 & 0.123 & 0.151 & 0.182 & 0.203 & 21.23 & 1.45 & 13.79 & 65 \\
\hline 30 & 0.113 & 0.130 & 0.161 & 0.191 & 17.69 & 1.75 & 11.40 & 85 \\
\hline
\end{tabular}


Table 2. Stimulation Techniques and Dose threshold with respective OSL readout time. (MDD for POSL and NL-OSL are reported in McKeever et al., 1996 and Mishra et al., 2011b respectively).

\begin{tabular}{|c|c|c|c|}
\hline $\begin{array}{l}\text { Stimulation } \\
\text { Techniques }\end{array}$ & $\begin{array}{c}\text { Low Dose limit } \\
(\mu \mathrm{Gy})\end{array}$ & $\begin{array}{l}\text { Readout Time } \\
\text { (s) }\end{array}$ & $\begin{array}{l}\text { Power Used } \\
\left(\mathrm{mW} / \mathrm{cm}^{2}\right)\end{array}$ \\
\hline$\overline{C W}-\mathrm{OSL}$ & 20.00 & 90 & 48 \\
\hline POSL & 5.00 & 1 & 48 \\
\hline LM-OSL & 15.38 & 90 & 48 \\
\hline NL-OSL & 12.80 & 90 & 48 \\
\hline TA-CWOSL & 11.40 & 90 & 30 \\
\hline
\end{tabular}

CW-OSL: Continuous wave-optically stimulated luminescence, POSL: Pulsed optically stimulated luminescence,

LM-OSL: Linearly Modulated optically stimulated luminescence, NL-OSL: Non-linearly optically stimulated luminescence,

TA-CWOSL: Thermally assisted- continuous wave optically stimulated luminescence.

\section{TA-OSL: EXTENSION OF DOSE LINEARITY}

The deeper defects of $\alpha-\mathrm{Al}_{2} \mathrm{O}_{3}: \mathrm{C}$ were studied using TA-OSL method to study the dose response of the phosphor. In order to record the TA-OSL response of deep traps, the sample was first subjected to TL readout up to a temperature of $400^{\circ} \mathrm{C}$ to deplete the signal due to $185^{\circ} \mathrm{C}$ main dosimetry TL peak. The sample was subsequently subjected to CW-OSL readout along with simultaneous application of temperature profile at a linear heating rate at $4 \mathrm{~K} / \mathrm{s}$. As a result two well-defined TA-OSL peaks at $121^{\circ} \mathrm{C}$ and at $232^{\circ} \mathrm{C}$ occur in time as well as temperature domain which are different from the main dosimetric TL peak which occurs at $\sim 185^{\circ} \mathrm{C}$ (Fig. 6a, 6b). The linearity of the integrated TA-OSL signal has been measured as a function of absorbed dose and found to be linear in the

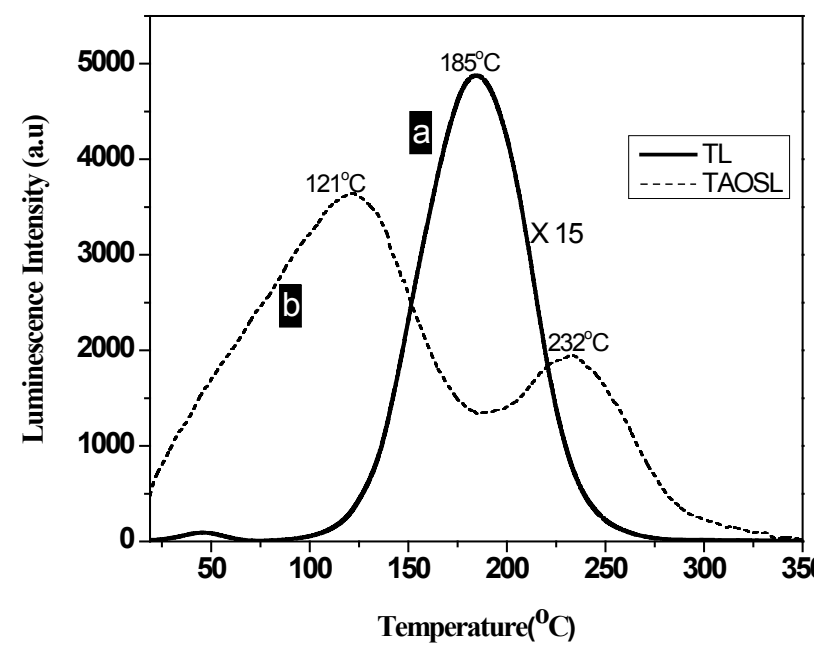

Fig. 6. a) TL glow curve recorded just after irradiation $500 \mathrm{mGy}$ of $\beta$ dose; b) TA-OSL curve taken after TL readout recorded at $48 \mathrm{~mW} / \mathrm{cm}^{2}$ stimulation light along with TL heating at $4 \mathrm{k} / \mathrm{s}$. dose range of 0.1 to $10 \mathrm{kGy}$ as shown in Fig. 7. Hence the dose linearity of $\mathrm{Al}_{2} \mathrm{O}_{3}: \mathrm{C}$ has been extended up to $10 \mathrm{kGy}$ which earlier was up to $1 \mathrm{~Gy}$ only. The MDD was found to be $10 \mathrm{mGy}$ using the in-house developed TL/OSL reader (Kulkarni et al., 2007). However, it can be further improved on improving the sensitivity of the reader system by using quartz window PMT. It was found that to erase the OSL signal from these defects one must apply thermal treatment at temperature of $\sim 400^{\circ} \mathrm{C}$ along with high intensity of light stimulation power or otherwise the sample has to be annealed at $900^{\circ} \mathrm{C}$, however, the former is preferred from the practical considerations. Therefore, even in extreme environment of temperature of about $400^{\circ} \mathrm{C}$, these deep traps were found to hold the stored information, if not exposed to intense light. Hence, handling of these samples in room light does not affect appreciably the signal from deeper traps. Due to these properties of deep traps, the TA-OSL technique can be used to assess the dose from previously irradiated dosimeter even if the main OSL traps have been inadvertently bleached due to heat or light, thus proving its capability for accidental and retrospective dosimetry. Further, using TA-OSL method these deep traps are accessible at 121 and $232{ }^{\circ} \mathrm{C}$, which otherwise could be detected by Phototransfered TL (PTTL) (Akesrold et al., 1993), or direct TL measurement up to $600-650^{\circ} \mathrm{C}$ for the first deep trap and up to $900^{\circ} \mathrm{C}$ for second deep trap. However, it is very difficult to record these high temperatures TL peaks by direct TL measurement due to the very high thermal quenching in $\alpha-\mathrm{Al}_{2} \mathrm{O}_{3}: \mathrm{C}$ and high infrared background at such higher temperatures. However, the TA-OSL measurements require normal TL-OSL reader, having simultaneous TL and OSL readout facility which is also available in commercial Risø reader (Bøtter-Jensen et al., 2000).

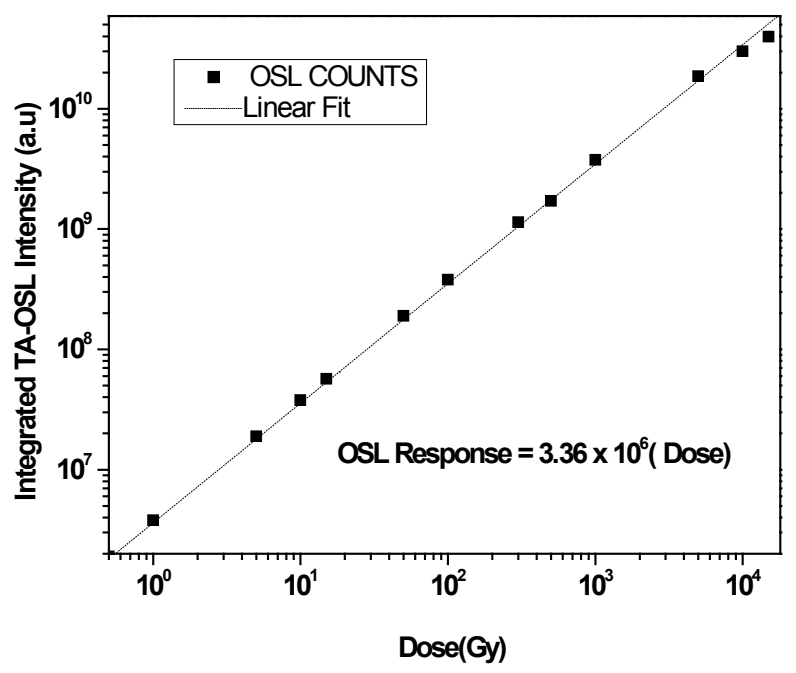

Fig. 7. Integrated TA-OSL dose response from deep traps of $\alpha-\mathrm{Al}_{2} \mathrm{O}_{3}: \mathrm{C}$. 


\section{CONCLUSIONS}

Electron-phonon interactions have been shown to be a possible reason for the dependence of the OSL decay on temperature. The MDD was found to improve by a factor of 1.8 by taking advantage of such interaction. The dose vs. TA-OSL response from deep traps of $\alpha-\mathrm{Al}_{2} \mathrm{O}_{3}: \mathrm{C}$ was found to be linear up to $10 \mathrm{kGy}$, thus extending its application for high dose dosimetry. Hence the dose linearity $\alpha-\mathrm{Al}_{2} \mathrm{O}_{3}: \mathrm{C}$ has been stretched in both directions using the TA-OSL method. By using this method, further study on material such as quartz and feldspar will help in extending the dose range of these materials for archaeological and geological dating applications.

\section{REFERENCES}

Akselrod MS, Kortov VS, Kravetsky DJ and Gotlib VI, 1990. Highly sensitive thermoluminescent anion defective $\alpha-\mathrm{Al}_{2} \mathrm{O}_{3}: \mathrm{C}$ single crystal detectors. Radiation Protection Dosimetry 32(1): 15-20.

Akselrod MS, Agersnap Larsen N, Whitley V and McKeever, SWS, 1998. Thermal quenching of F-center luminescence in $\alpha-\mathrm{Al}_{2} \mathrm{O}_{3}: \mathrm{C}$. Journal of Applied Physics 84(6): 3364-3373, DOI $10.1063 / 1.368450$.

Akesrold MS, and Gorelova EA, 1993. Deep traps in highly sensitive $\alpha$ $\mathrm{Al}_{2} \mathrm{O}_{3}$ : C TLD Crystals. Nuclear Tracks and Radiation Measurements 21(1): 143-146, DOI 10.1016/1359-0189(93)90065-H.

Bailey RM, 2001. Towards a general kinetic model for optically and thermally stimulated luminescence of quartz. Radiation Measurements 33(1): 17-45, DOI 10.1016/S1350-4487(00)00100-1.

Bøtter-Jensen L, Bulur E, Duller GAT and Murray AS, 2000. Advances in luminescence instrument systems. Radiation Measurements 32(5-6): 523-528, DOI 10.1016/S1350-4487(00)00039-1.

Hütt G, Jaek I and Tchonka J, 1988. Optical dating: K-feldspars optical response stimulation spectra. Quaternary Science Reviews 7(3-4):
381-385, DOI 10.1016/0277-3791(88)90033-9.

Kulkarni MS, Mishra DR and Sharma DN, 2007. A versatile integrated system for thermoluminescence and optically stimulated luminescence measurements. Nuclear Instruments and Methods in Physics Research Section B: Beam Interactions with Materials and Atoms 262(2): 348-356, DOI 10.1016/j.nimb.2007.05.013.

Markey BG, McKeever SWS, Akselrod MS, Botter-Jensen L, Agersnap Larsen N and Colyott LE, 1996. The temperature dependence of optically stimulated luminescence from $\alpha-\mathrm{Al}_{2} \mathrm{O}_{3}$. Radiation Protection Dosimetry 65: 185-189.

McKeever SWS, Akselrod MS and Murkey BG, 1996. Pulsed optically stimulated luminescence dosimetry using $\alpha-\mathrm{Al}_{2} \mathrm{O}_{3}: \mathrm{C}$. Radiation Protection Dosimetry 65: 267-272.

McKeever SWS, B $\phi$ tter-Jensen L, Agersnap Larsen N and Duller GAT, 1997. Temperature dependence of OSL decay curves experimental and theoretical aspects. Radiation Measurements 27(2): 161-170, DOI 10.1016/S1350-4487(96)00106-0.

McKeever SWS and Morris MF, 1994. Computer simulations of optical bleaching of TL and OSL signals. Radiation Measurements 23(23): 301-306, DOI 10.1016/1350-4487(94)90056-6.

Mishra DR, Soni A, Rawat NS, Kulkarni MS, Bhatt BC and Sharma DN, 2011a. Method of measuring thermal assistance energy associated with OSL traps in $\alpha-\mathrm{Al}_{2} \mathrm{O}_{3}: \mathrm{C}$ phosphor. Radiation Measurements 46(8): 635-642, DOI 10.1016/j.radmeas.2011.05.069.

Mishra DR, Kulkarni MS, Rawat NS, Soni A, Bhatt BC and Sharma DN, 2011b. Preliminary Non-Linear Light Modulation OSL Studies using $\alpha-\mathrm{Al}_{2} \mathrm{O}_{3}$ : C. Radiation Measurements 46(12): 1462-1468, DOI 10.1016/j.radmeas.2011.06.013.

Poolton NRJ, Bøtter-Jensen L and Johnsen O, 1995. Thermo-optical properties of optically stimulated luminescence in feldspar. Radiation Measurements 24(4): 531-534, DOI 10.1016/13504487(94)00114-G.

Spooner NA, 1994. On the optical dating signal from quartz. Radiation Measurements 23(2-3): $\quad 593-600, \quad$ DOI $\quad 10.1016 / 1350-$ 4487(94)90105-8.

Yukihara EG, Whitley VH, Polf JC, Klein DM, McKeever SWS, Akselrod AE and Akselrod MS, 2003. The effects of deep trap population on the thermoluminescence of $\mathrm{Al}_{2} \mathrm{O}_{3}: \mathrm{C}$. Radiation Measurements 42(4-5): 627-638, DOI 10.1016/j.radmeas.2007.01.054. 